Int. J. Electrochem. Sci., 13 (2018) 9999 - 10022

International Journal of

ELECTROCHEMICAL

SCIENCE

www.electrochemsci.org

\title{
Mathematical Models of the Infinite Porous Rotating Disk Electrode
}

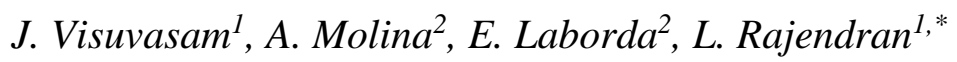

${ }^{1}$ Academy of Maritime Education and Training(AMET), Deemed to be University, Department of Mathematics, Kanathur- 603112, India

${ }^{2}$ Department of Physical Chemistry, University of Murcia, 30100 Murcia, Spain.

*E-mail: raj_sms@ @ediffmail.com

doi: $10.20964 / 2018.10 .35$

Received: 27 April 2018 / Accepted: 29 May 2018 / Published: 1 September 2018

An analytical expression of the current generated from the electrochemical reaction in a porous rotating disk electrode (PRDE) is derived when the reactant transport is dominated by advection and diffusion. Simple algebraic expressions for the concentration of reactant and the current response are obtained as a function of the rotation rate, reaction rate, permeability of the porous medium, diffusion coefficients, kinematic viscosity, and geometry of the porous film. Upon comparison, the analytical expression of current in this work coincides with the existing results for the limiting case of low rotation rates. Also the concentration/current expressions here derived are in satisfactory agreement with numerical results.

Keywords: Mathematical modelling, Porous rotating disk electrode, Non-linear convection diffusion equation, Homotopy perturbation method.

\section{FULL TEXT}

(C) 2018 The Authors. Published by ESG (www.electrochemsci.org). This article is an open access article distributed under the terms and conditions of the Creative Commons Attribution license (http://creativecommons.org/licenses/by/4.0/). 